\title{
La Prueba de la Sulfofenolfraleina para la Permeabilidad Tubaria o Test de Speck
}

\author{
Doctor Eduardo Acosta-Bendek. M. D. \\ De la Sociedad de Obstetricia y Ginecologia del Atlántico - Barranquilla.
}

En la esterilidad femenina, la determinación de la permeabilidad tubaria constituye un factor de fundamental importancia, por la trecuensia con que se encuentran obstrucciones causantes de la esterilidad. Segun estadísticas de diferentes autores, llega a ser única responsable en un $30 \%$ a $60 \%\left({ }^{4}\right)$; de aquí que se considere de un gran interés tanto de diagnóstico, como de pronóstico su correcta valoración. Por este motivo muchos han sido los investigadores que han tratado de conseguir métodos o procedimientos que den maror margen de seguridad e inosuidad.

Hay un sinnúmero de lesiones tubarias que escapan al más meticuloso examen ginecológico, aún en manos muy expertas, ya que no se acompañan de modificaciones de volumen o de consistencia, tales son las obliteraciones del ostium uterino, los espasmos del itsmo, acodaduras, estrangulaciones, oclusión de los orificios abdominales, etc. Teniendo que acudir a algunos de los métodos usados actualmente para la prueba de la permeabilidad tubarica como son: la HISTEROSALPINGOGRAFIA, con prueba de Cotte; si es necesario, el SALPINGOQUIMOGRAMA o por el método de RUBIN de persuflación de aire, o mejor de anhídrido carbónico. No obstante, son muchos los investigadores, que en los últimos años, han tratado de conseguir métodos mas simples y sencillos. y que sean suficientemente exactos, como lo es la prueba de SPECK, a la cual nos ramos a referir en este escrito. leína)".

"En qué consiste la prueba de SPECK o test de la PSP (Sulfofenolfta-

George SPECK en el año de 1948 publicó unas 24 observaciones en las que investigó la permeabilidad tubaria por medio de una solución de sulfofenolftaleína. Fue escogida esta sustancia por ser considerada libre de toxicidad, y por tener una velocidad de absorción a través del peritoneo mayor que la de la 
mucosa vaginal, del endocérvix, endometrio y endosalpinx, siendo esta propiedad la base del test propuesto. Dicho colorante es inyectado en la cavidad uterina, y si las trompas son permeables cae en la cavidad peritoneal, de donde es ab. sorbidorápidamente para ser eliminado por los riñones, entonces la vejiga es cateterizada a los 10 y 30 minutos y la orina recolectada se pone en contacto con unas cinco gotas de una solución de hidróxido de sodio al 10\%, la cual virará al rnsado o rojo si el colorante está presente en la orina, considerando así las trompas permeables.

Para comprobar el poder de absorción del colorante en el peritoneo, SPECK (5) llevo a cabo los experimentos siguientes en conejos asi: inyectó $6 \mathrm{mgs}$. de PSP (sulfofenolftaleína) dentro de la cavidad peritoneal de 6 conejos y recolectaba la orina cada cinco minutos; en cada uno de los casos el colorante fue encontrando en la orina dentro de los 25 a 30 minutos, comprobando así la absorción rápida de la PSP a través del peritoneo de los conejos. Para demostrar si dicho colorante era fácilmente absorbido a través de la mucosa vaginal, del endo. cérvix, endometrio y endosalpinx, sometió a esta prueba a una paciente voluntaria, que hacía dos años se le había ligado las trompas por el método de Pomery, asi: diluyó 12 mgs. de PSP en 20 c.c. de solución isotónica de cloruro de sodio y los puso en contacto con la cavidad vaginal por 2 horas, al final de este tiempo el cororante no apareció en la orina; luégo disolvio 6 mgs. de PSP en 10 c.c. de la misma solución anterior y lo inyectó en la cavidad uterina, y después de una hora el colorante no estaba presente en la orina. Tomó otra paciente voluntaria, a quien se le habia comprobado la permeabilidad de las trompas y le invectó la misma cantidad anterior de la solución en la cavidad uterina, apareciendo el colorante en la orina antes de los 30 minutos: conclurendo, que el colorante tuvo que haber pasado a través de las trompas a la caridad peritoneal, ser absorbida por ésta y pasar por medio de la sangre al riñon. para ser excretada por la orina en cantidad suficiente y dar una reaccion positiva del test.

SPECK ( 5 ) hace notar, que, si el colorante es absorbido a traves de la mucosa de la vagina, cérvix, útero o trompa, lo hace muy lentamente y en pequeñas cantidades o nada, así que, cualquier absorción que pueda ocurrir no interfiere e] test, si éste se lleva a cabo dentro de los 30 minutos.

\section{TÉCNICA}

I a técnica empleada en las observaciones clinicas fue la siguiente: paciente en posición ginecológica, se coloca un espéculum $y$ se hace la asepsia de la vagina y del cérvix. Se toma el labio anterior cervical con unas pinzas erinas y con un histerómetro se sondea la cavidad uterina con el objeto de comprobara que no haya una estenosis del orificio interno. Se introduce el cono tipo tornillo de la cánula de HUDGINS (Fig. 1, letra C). conducido por el tallo director (Fig. 1, letra A), en el orificio cervical externo. dándole vuelta a la manera de un tornillo hasta ajustarlo bien al orificio con el fin de evitar cualquier escape de la solución inyectada, una vez bien fijo se retira el tallo director y se conecta el tallo hueco o de extension (Fig. 1, letra B), que a su 
vez va a conectarse a una jeringa de 10 c.c. que contiene 6 mgs. de PSP disueltos en 9 c.c. de una solución isotónica de cloruro de sodio y se inyecta lentamente en la cavidad uterina; se retira inmediatamente la jeringa con su tallo de extensión; el cono tipo tornillo, el espéculum y las pinzas erinas se rétiran al final de los 10 minutos: La vejiga se cateteriza al final de los 15 minutos de haberse inyectado la solución colorante, la orina recogida se pone en contacto con unas cinco gotas de una solución de hidróxido de sodio al $10 \%$ y se puede obtener un color rosado o rojo, de acuerdo a la cantidad del colorante presentc en la orina, si las trompas son permeables. Si la orina permanece clara, se le da un vaso con agua a la paciente, y se cateteriza nuevamente la vejiga $15 \mathrm{mi}$ nutos más tarde y si no vira el color de la orina en presencia de la solución alcalina, la prueba es negativa, e indica que las trompas no son permeables.

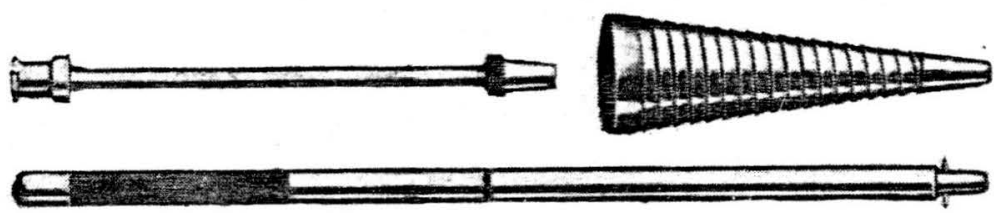

\section{Contraindicaciones}

a) Infección del tracto genital, aguda o subaguda o crónica.

b) Embarazo.

c) Hemorragias uterinas.

d) Procesos neoplásicos.

\section{ExPERIENCLA CLÍNICA}

Debido a la premura del tiempo solamente me fue posible realizar 19 exploraciones clínicas de la permeabilidad tubaria con el Test de SPECK, 7 de as cuales fueron comprobadas quirúrgicamente y 12 por medio de la Histerosalpingografía.

Para el Test de SPECK utilicé la Cánula de HUDGINS, por ser de fáci! manejo, adaptarse muy bien al orificio uterino y de técnica muy sencilla. Una ampolleta de Sulfofenolftaleína de 6 mgs. por c.c., y que disolvía en 9 c.c. de una solución isotónica de cloruro de sodio. El sondeo vesical lo praticaba a los 15 y 30 minutos después de la invección del colorante. Todas las pruebas fueron verificadas en el post-menstruo inmediato, $y$ a todas las enfermas se les pracicó examen de orina, el cual fue normal.

Para la Histerosalpingografía empleé como medio de contraste una mezla de Lipiodol-Eter en la proporción de 6.1, (lipiodol al 40\% de yodo, con éter sulfúrico purísimo) con muy buenos resultados; según A. KARCZMAR (12), el éter al aumentar la tensión superficial del aceite yodado permite un mayor contacto del material de contraste con la mucosa de la matriz y por su mayor fluidez 
franquea sin violencia las estrececes de la trompa, como también la absorción et la pelvis se efectúa más rápidamente, que cuando se usa el Lipiodol sólo. Dice KARCZMAR, "que la mezcla descrita posee propiedades bacteriostáticas y probablente curativas de focos sépticos tubáricos larvados; no es irritante, ni produce inflamación en los genitales externos, ni en el peritoneo".

Para la invección del medio de contraste en la Histerosalpingografía utilice la misma Cánula de HUDGINS, con buenos resultados. Las histerosalpingografías fueron efectuadas a las 24 ó 48 horas después de haber practicado el Test de SPECK

No se registró accidente, ni complicación de ninguna naturaleza, como tam poco ninguna de las pacientes experimentó molestia alguna en el curso de la prueba. De las 12 histerosalpingografías, en 10 usé la mezcla Lipiodol-éter, como medio de contraste y en las 2 restantes sólo emplée el Lipiodol, observándose en las primeras la absorción del medio de contraste más rápido que en las segundas.

\section{ANÁlisis de los RESUILTADOS:}

Con el objeto de establecer el valor comparativo de la prueba de SPECK con los orros dos métodos empleados, he seguido el orden siguiente:

a) Coincidencia de los resultados entre la prueba de SPECK y la comprobación quirúrgica.

Observación $N^{o}$ 1.-Paciente: N. D., 25 años, ha tenido 2 hijos y un aborto. Test de la PSP, negativo a los 15 y 30 minutos. Se observó resitencia a la entrada del colorante. Comprobación quirúrgica. Se encontró ambas trompas obstruídas por un proceso anexial crónico.

Observación No 2.-Paciente: N. C., 39 años, 4 hijos. Test de la PSP, positivo a los 15 × 30 minutos. No hubo resistencia a la entrada de la solución. Comprobación quirúrgica. Trompa izquierda permeable, y derecha obstruíada por un hidrosalpinx.

Observacion No 3.-Paciente: N. D., 25 años, un hijo y un aborto. El Test de la PSP, dio negativo a los 15 y positivo a los 30 minutos. Hubo un ligero escape de la solucion. Comprabación quirúrgica. Permeabilidad bilateral de las trompas.

Observación No 4.-Paciente: N. N., 15 hijos, un aborto. Test de la PSP negativo a los 15 minutos y positivo a los 30 . Se presentó un ligero escape de la solución, y ésta entró sin resistencia alguna. Comprobación quirúrgica. Per meabilidad de las trompas bilaterales.

Observación N? 5.-Paciente: N. N., 22 años, un aborto. Test de la PSP negativo a los 15 y 30 minutos. Resistencia a la entrada del colorante, el liquido refluyó unos 2 c.c. Comprobación quirúrgica. Trompas obstruíadas bilateralmente por antiguo proceso anexial.

Observación No 6.-Paciente: N. D., 32 años, 2 hijos. Test de la PSP po sitivo a los 15 y 30 minutos. La solución entrú muy suavemente. Comprobación quirúrgica. Trompa izquierda obstruída por un proceso inflamatorio cronico, 
además de estar adherida en forma de caracol a un quiste del ovario del mismo lado. La trompa derecha estaba permeable.

Observación No 7.-Paciente: N. N., 21 años, nulípara. Test de la PSP negativo a los 15 y 30 minutos. Comprobación quirúrgica. Trompas bilaterales obstruídas por proceso inflamatorio crónico.

Las siete intervenciones quirúrgicas que he presentado fueron intervenidas por lesiones de los anexos o matriz. La permeabilidad de las trompas fue comprobada en todas las enfermas por el método de la insuflación retrógrada.

b) Coincidencia de los resultados entre la Prueba de SPECK y la Histerosalpingografía.

Observación No 8.-Paciente: N. N., 32 años, 7 hijos, un aborto. Test de la PSP positivo a los 15 y 30 minutos. La Histerosalpingografía reveló permeabilidad de la trompa izquierda y obstrucción de la derecha. No hubo resistencia a la invección del medio de contraste.

Ob́servación No 9.-Paciente: N. N., 43 años, 8 hijos, 2 abortos. Test de la PSP positivo a los 15 y 30 minutos. Histerosalpingografía comprobó la permeabilidad bilateral de las trompas. El medio de contraste se inyectó sin resistencia alguna.

Observación No 10.-Paciente: N. N., 43 años, 2 hijos. Test de la PSP positivo a los 30 minutos y negativo a los 15. La solución refluyó unos 2 c.c. La Histerosalpingografía reveió permeabilidad bilateral de las trompas.

Observación N ${ }^{\circ}$ 11.-Paciente: N. N., 28 años, 4 hijos. Test de la PSP positivo a los 15 y 30 minutos. La Histerosalpingografía comprobo la permeabilidad bilateral de las trompas. El medio de contraste entró sin resistencia alguna.

Observación No 12.-Paciente: N. N., 38 años, 8 hijos, un aborto. Test de la PSP positivo a los 15 y 30 minutos. Histerosalpingografía comprobó permeabilidad bilateral de las trompas. El medio de contraste se invecto sin resistencia alguna.

Observación No 13.-Paciente: N. D., de 23 años, un hijo hace 8 años. Operada de anexitis hace año y medio. Test de PSS negativo a los 15 y $30 \mathrm{mi}$ nutos, sólo pudo inyectarse unos 6 c.c. debido a la resistencia a la entrada de la solución y la enferma se quejaba del dolor. La Histerosalpingografia fue negativa, y se inyectó solamente del medio de contraste 5 c.c.: debido al obstáculo presentado no permitió continuar la invección, ya que el dolor producido era fuerte, debido a la probable salpingectomía bilateral por su anexitis. La Histerosalpingografía reveló trompas obstruídas bilateralmente.

Observación No 14.-Paciente: N. D., 20 años, 2 hijos, hace 10 meses tuvo el último. Test de la PSP positivo a los 15 y 30 minutos. El líquido colorante entró sin resistencia alguna. La Histerosalpingografía comprobó la permeabilidad de las trompas, el medio de contraste entró sin resistencia.

Observación No 15.-Paciente: N. D., 28 años, 9 hijos, último hace 8 me. ses. Test de la PSP positivo a los 15 y 30 minutos. La solución colorante entró sin resistecnia alguna. La Histerosalpingografía demostró la permeabilidad bilateral de las trompas. 
Observación No 16.-Paciente: N. N., 35 años, 4 hijos, 2 abortos, último hijo hace 18 años. Test de la PSP positivo a los 15 y 30 minutos. La Histerosalpingografía reveló la permeabilidad de ambas trompas.

Observación N? 17.-Paciente: N. D. 29 años, 3 hijos, último hace 5 meses. Test de la PSP positivo a los 15 y 30 minutos; la solución colorante entró sin resistencia alguna. La histerosalpingografía comprobó la permeabilidad de las trompas, después de haberse inyectado 10 c.c. del medio de contraste.

Obserración No 18.-Paciente de 23 años, 2 hijos, último hace 4 años. Test de la PSP a los 15 y 30 minutos positivo. La solución entró sin resistencia alguna. La Histerosalpingografía comprobó la permeabilidad bilateral de las trompas.

Observación No 19.-Paciente de 21 años, 2 hijos, último hace 3 años. Hace 20 días le fue practicada la salpingectomía bilateral por proceso anexial crónico. Test, de la PSP positivo a los 15 y 30 minutos. La Histerosalpingografía revelo la obstrucción bilateral de las trompas. Tanto del colorante, como del medio de contraste sólo se pudo invectar 5 c.c. debido a la gran resistencia presentada a la inyección al llegar a esta cantidad, y por temor a producir una rupruptura de los tubos.

\section{Comentarios}

De las 19 observaciones presentadas, sólo en la última, la Prueba de Speck no estuvo de acuerdo con los resultados quirúrgicos y de la histerosalpingografía; probablemente dicha falla de la PSP se debió a la posibilidad de una mavor absorción de la sulfofenoltaleína por las mucosas inflamadas de la trompa y matriz, ya que tal prueba fue practicada a los 20 dias de la salpingectomia. Esta posibilidad de rapida absorción del colorante por las mucosas inflamadas fue aceptada por Daris ${ }^{14}$ ) y colaboradores, en una evaluacion que hizo sobre este Test en 110 pacientes comparados con la insuflacion y la histerosalpingografía el año pasado.

\section{Conclusiones}

a) Por los resultados anteriormente obtenidos, considero la Prueba de SPECK como un procedimiento de gran utilidad para la comprobación de la permeabilidad tubaria.

b) Es un Test bastante exacto, fácil de realizar, y de interpretación sencilla, por lo tanto puede practicarse en el consultorio sin ningún inconveniente.

c) Como no se necesita para su ejecución e interpretación de aparatos especiales, lo considero de gran utilidad práctica en los centros rurales.

d) En ninguno de los casos presentados. se observó molestia o inconveniente alguno, siempre guardando los cuidados de asepsia que se requieren para estas pruebas, por lo tanto considero la Prueba de SPECK como inofensiva y sin riesgo alguno para las pacientes. 
e) Por la sencillez de la técnica, el fácil manejo y lo poco traumatizante para la enferma, considero la Cánula de Hudgins como un instrumento de mucha utilidad para la realización del Test de la PSP e Histerosalpingografias.

Expreso mis sinceros agradecimientos al doctor Víctor Londoño, radiólogo del Hospital de Barranquilla, por la colaboración prestada en los estudios radiográficos de este trabajo.

Barranquilla, agosto 28 de 1953.

\section{B I B L I O G R A F I A}

1.-V. Conill Montabio: "Tratado de Ginecología y de Técnica Terapéutica Ginecológica". Segunda edición. Págs. 171-172; 1950.

2.-Carlos J. Calatroni y Vicente Ruiz: "Terapéutica Ginecológica”. Segunda edición. Págs. 1.033-1.038; 1946.

3.-H. Sturgeon Crossen y Robert James Crossen: "Enfermedades de la mujer". Tomo I, págs. $226-227 ; 1946$.

4.-."Semana Médica Argentina". Tomo 99: 336; 1951.

5.-George Speck: J. A. M. A. 143: 357; 1950.

6.-Karshmer. N. and Stein W.: A. M. J. Obst. and Gynec., 61: 458; 1951.

7.-Speck G.: A. M. J. Obst. and Gynec. 55: 1.048; 1948.

8.-E. M. Rosset: A. M. J. Obst. and. Gynec. 60: 1.892; 1950.

9 - -I. C. Rubin. F. A. C. S. and Ernest Myller: A. M. J. Obst. and Gynec. 56: 1.077;

10.-Clayton, T. Beechman and Mrray D. Sigman: A. M. J. Obst. and Ginec. 56: $935 ; 1948$.

11. - "Semana Médica Argentina". Tomo 99, № 8.

12 . -"Sinópsis Médica Internacional". Noviembre 1952.

3. -W. Stoeckel: "Tratado de Ginecología". Cuarta edición española. Págs 732$735 ; 1948$

14.-Davis, M. E., Ward, M. E. and King, A. G.: A. M. J. Obst. and Gynec. 66: 227. julio 1953.

15. - "Year Book of Obstetrics and Gynecology”. Págs. 315-353; 1952. 